\title{
A Case Report of a Rapidly Growing Giant Pilomatrixoma on the Posterior Shoulder in a 12-Year-Old Male Patient
}

\author{
Andjela Egger Yumeng Li Mercedes E. Gonzalez \\ Dr. Phillip Frost Department of Dermatology \& Cutaneous Surgery, University of Miami Miller School of \\ Medicine, Miami, FL, USA
}

\section{Established Facts}

- Only around 30 cases of giant pilomatrixoma have been reported in the literature, with most of them occurring on the head, neck, and upper extremities.

- Giant pilomatrixomas are benign tumors larger than $5 \mathrm{~cm}$ that usually exhibit slow growth over several years.

\section{Novel Insights}

- In addition to head, neck, and upper extremities, giant pilomatrixomas can occur on the back. Differential diagnosis of a large tumor on the back of a male child patient should include giant pilomatrixoma.

- Our case is a unique presentation of a benign giant pilomatrixoma on the back growing at an alarming rate within months. Ruling out a malignant process in the instance of such rapid growth is of utmost importance.

\section{Keywords}

Pilomatrixomas · Giant pilomatrixomas · Benign calcifying epithelioma of Malherbe · Mass

\section{Abstract \\ Introduction: Giant pilomatrixomas are quite rare and can be clinically challenging to diagnose. Case Presentation: Here, we report a case of a rapidly growing mass on the shoulder of a 12-year-old previously healthy boy. The lesion on his right shoulder appeared as a painless, pink-blue- colored solitary mass that started 6 months ago and rapidly}

enlarged to $4.5 \times 6 \mathrm{~cm}$ in size. Previous biopsy results were inconclusive, showing only hypercellular spindle cell proliferation in a collagenous stroma. There was concern for malignancy versus mixed lymphatic venous malformation or benign soft tissue tumor. An excisional biopsy was done and demonstrated features of a pilomatrixoma. Complete surgical removal with clear margins was curative. Conclusion: Diagnosis and management of rapidly enlarging skin lesions in children can be difficult for clinicians and dermatopathologists. Excisional biopsy can be both diagnostic and therapeutic. A timely exclusion of malignancy is of utmost importance.

(c) 2020 S. Karger AG, Base

$\begin{aligned} & \text { karger@karger.com } \\ & \text { www.karger.com/sad }\end{aligned}$
Karger ${ }^{\prime /}$




\section{Introduction}

Pilomatrixoma or benign calcifying epithelioma of Malherbe is a common, benign tumor of hair follicle matrix cells. These lesions usually occur on the head and neck regions and are usually $<3 \mathrm{~cm}$ in largest dimension [1]. Giant pilomatrixoma is a rare presentation of this benign tumor when the lesion is $>5 \mathrm{~cm}$ in size. The radiological features are nonspecific and may be clinically difficult to differentiate from malignant tumors. Here, we describe the case of a healthy young boy who presented with a rapidly enlarging giant pilomatrixoma that recurred after initial excision. Through this case, we hope to raise awareness of this rare entity, especially when it is not located on the head and neck, and the importance of complete removal to prevent recurrence.

\section{Case Report/Case Presentation}

The patient is a 12-year-old boy with no prior medical history who presented with a large, asymptomatic tumor on the posterior aspect of the right shoulder that started 6 months ago and continued to grow rapidly. Review of systems was otherwise negative. He presented to an outside dermatologist 6 weeks prior and had a punch biopsy that was nonspecific, showing hypercellular spindle cell proliferation in association with loose collagenous stroma and telangiectasias. The lesion was subsequently "excised" at the same outside office and showed fragments of a ruptured pilomatrixoma. However, the lesion grew back even larger within a span of 6 weeks. On presentation, there was a $4.5 \times 6-\mathrm{cm}$, firm, exophytic, relatively mobile, pink-blue mass, with a cystic component and a firm, central nodule on palpation (Fig. 1). He denied any personal or family history of similar tumors or genetic conditions. Clinical decision was made to perform an excisional biopsy on the same day due to concern for pilomatrical carcinoma. Other differentials included pilomatrixoma, sarcoma, calcified hemangioma, or mixed lymphatic venous malformation. Histological analysis was finalized after consultation with a soft tissue tumor specialist, and demonstrated aggregates of ghost cells engulfed by multinucleated foreign body type-giant cells, granulation tissue, and prominent reactive neovascularization consistent with residual pilomatrixoma with reactive vascular tissue (Fig. 2). No neoplasm was visualized. The excisional biopsy with clear margins was curative with no recurrence after 7 months.

\section{Discussion/Conclusion}

Pilomatrixoma, or benign calcifying epithelioma of Malherbe, is a common follicular tumor arising from the matrix cells. It was initially described by Malherbe and Chenatais in 1880 as a sebaceous gland tumor, and later identified by Forbis and Helwig to be a hair follicle tumor

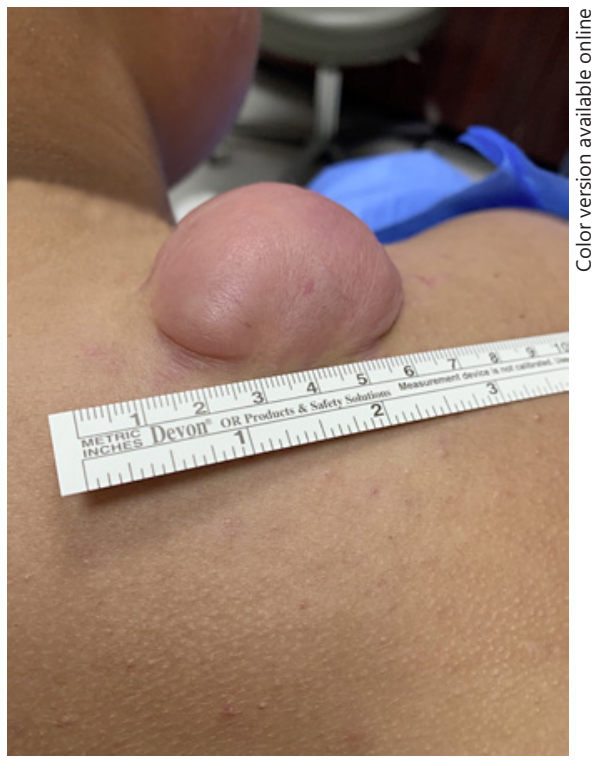

Fig. 1. A giant pilomatrixoma on the posterior shoulder in a 12 -year-old male patient presenting as a $4.5 \times 6-\mathrm{cm}$, firm, exophytic, relatively mobile, pink-blue mass, with a cystic component and a firm, central nodule on palpation.

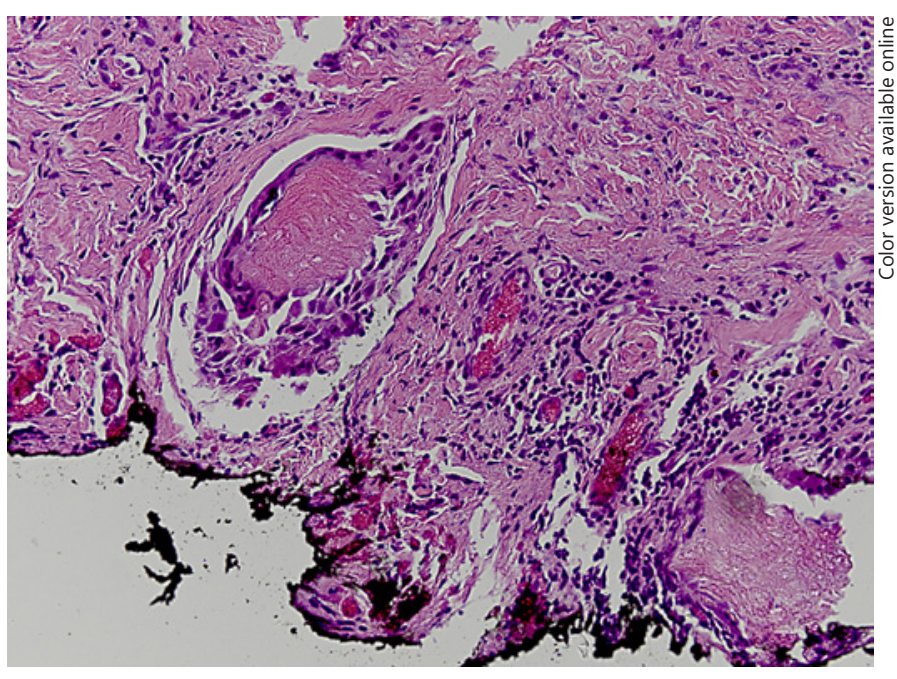

Fig. 2. Aggregates of ghost cells engulfed by multinucleated foreign body-type giant cells, granulation tissue, and prominent reactive neovascularization (H\&E, high power magnification). H\&E, hematoxylin and eosin.

in 1961 [2-4]. It has a bimodal distribution of presenting either within the first 2 decades of life or after the age of 60 years [4]. Majority of these lesions appear on the head or neck and are up to $3 \mathrm{~cm}$ in diameter [4-6]. The most common presentation is a single, tender, well-circumscribed, skin-colored or red/blue nodule on the face, 
head, or neck. However, other clinical variants have been reported, such as exophytic, bullous, anetodermic, lymphangiectatic, and ulcerating $[3,4,7,8]$. Multiple and familial-type pilomatrixomas have been described and can be associated with several different genetic syndromes, such as Rubinstein-Taybi syndrome, basal cell nevus syndrome, Turner's syndrome, Gardner's syndrome, xeroderma pigmentosum, or myotonic dystrophy $[4,6,8]$.

Giant pilomatrixomas are pilomatrixomas larger than $5 \mathrm{~cm}[4,5,9]$. The first case was described by Krausen et al. [9]. Given its rarity, only around 30 cases of giant pilomatrixoma have been reported in the literature, with most of them occurring in male patients on the head, neck, and upper extremities $[2,8]$. Moreover, they are thought to be associated with more complications such as ulcerations and secondary infections than normal pilomatrixomas, presumably secondary to trauma [3]. Histologically, pilomatrixomas and giant pilomatrixomas are similar. Biopsy of these tumors usually show a cystic component, containing a collection of basaloid cells, calcification in up to $75 \%$ of lesions, transitional cells, matrical cornification with ghost cells, and foreign body-type multinucleated giant cells [10].

Malignant transformation of pilomatrixoma is rare and usually occurs in patients older than 40 years. There are activating mutations in exon 3 of the CTNNB1 gene in malignant pilomatrixomas which may drive their pathogenesis [11]. There have been no reports to suggest an increased rate of malignant transformation in giant pilomatrixomas. Histopathological differentiation between pilomatrixoma and its malignant counterpart can be challenging, with the key being cellular pleomorphism and increased mitotic rate of up to 20 per high-power field [12].

Diagnosis of pilomatrixoma and giant pilomatrixoma is usually based on incisional or excisional biopsy, although fine needle aspiration cytology (FNAC) has been used as a preoperative diagnostic tool. Depending on the cell types that are aspirated, results from the FNAC can be misleading, since the nuclear atypia and basaloid cells can erroneously be attributed to several malignant neoplasms [13]. CT scan and MRI of pilomatrixomas can yield nonspecific findings, usually a subcutaneous mass with heterogeneity and calcification that can lead to a wide range of differential diagnoses. Treatment of pilomatrixomas is local excision with clear margins as there have been no reports of spontaneous regression. Incomplete resection can lead to recurrence, which is likely what occurred with our patient.
Our patient presented with a rapidly growing giant pilomatrixoma that recurred at an alarming rate after initial resection. Contrary to our case, a recent report of giant pilomatrixoma in an adolescent male demonstrated a much slower growth over 6 years [14]. In the setting of such rapid growth, ruling out a potential malignant transformation was our foremost concern. Given the abundant reactive tissue seen on histology, it is possible that the trauma from initial resection triggered the pilomatrixoma to rapidly proliferate. This is consistent with previous observations of pilomatrixomas occurring at sites of previous trauma [15].

Giant pilomatrixoma is a rare, benign entity that can mimic skin or soft tissue malignancies, especially when rapid growth is present. Diagnosis requires incisional biopsy or complete resection as FNAC may lead to erroneous diagnosis of malignancies. Complete excision is recommended, given the lack of spontaneous regression and potential regrowth. Giant pilomatrixomas should be considered in a differential in the setting of a large, solitary well-circumscribed lesion in children or adults, although pilomatrical carcinoma should be promptly excluded.

\section{Acknowledgement}

We would like to acknowledge Dr. George Elgart for photomicrographs included in this manuscript.

\section{Statement of Ethics}

The patient has given written informed consent to publish this case, including the publication of images. The document will be uploaded along with the manuscript.

\section{Disclosure Statement}

The authors have no conflicts of interest to declare.

\section{Funding Sources}

The authors did not receive any funding.

\section{Author Contributions}

Every author listed meets the qualifications for authorship and has had the opportunity to read and comment upon the submitted manuscript. 


\section{References}

1 Gongidi P, Meshekow J, Holdbrook T, Germaine P. Giant pilomatrixoma presenting in the posterior thorax, a rare location and the largest described. Case Rep Radiol. 2015; 2015:590742.

2 Zamanian A, Farshchian M, Farshchian M. Clinical and histopathologic study of pilomatricoma in Iran between 1992 and 2005. Pediatr Dermatol. 2008 Mar-Apr;25(2):2689.

3 Yamauchi M, Yotsuyanagi T, Saito T, Ikeda K, Urushidate S, Higuma Y. Three cases of giant pilomatrixoma: considerations for diagnosis and treatment of giant skin tumours with abundant inner calcification present on the upper body. J Plast Reconstr Aesthet Surg. 2010 Jun;63(6):e519-24.

4 Souto MP, Matsushita MM, Matsushita GM, Souto LR. An unusual presentation of giant pilomatrixoma in an adult patient. J Dermatol Case Rep. 2013 Jun 30;7(2):56-9.
5 Mundinger GS, Steinbacher DM, Bishop JA, Tufaro AP. Giant pilomatricoma involving the parotid: case report and literature review. J Craniomaxillofac Surg. 2011 Oct;39(7):51924.

6 Nadershah M, Alshadwi A, Salama A. Recurrent giant pilomatrixoma of the face: a case report and review of the literature. Case Rep Dent. 2012;2012:197273.

7 Lozzi GP, Soyer HP, Fruehauf J, Massone C, Kerl H, Peris K. Giant pilomatricoma. Am J Dermatopathol. 2007 Jun;29(3):286-9.

8 Do JE, Noh S, Jee HJ, Oh SH. Familial multiple pilomatricomas showing clinical features of a giant mass without associated diseases. Int J Dermatol. 2013 Feb;52(2):250-2.

9 Krausen AS, Ansel DG, Mays BR Jr. Pilomatrixoma masquerading as a parotid mass. Laryngoscope. 1974 Apr;84(4):528-35.
10 Black DS, Christodoulou G, Cole S. Mindfulness meditation and gene expression: a hypothesis-generating framework. Curr Opin Psychol. 2019 Aug;28:302-6.

11 Chan EF, Gat U, McNiff JM, Fuchs E. A common human skin tumour is caused by activating mutations in beta-catenin. Nat Genet. 1999 Apr;21(4):410-3.

12 Sau P, Lupton GP, Graham JH. Pilomatrix carcinoma. Cancer. 1993 Apr 15;71(8):2491-8.

13 Lemos MM, Kindblom LG, Meis-Kindblom JM, Ryd W, Willén H. Fine-needle aspiration features of pilomatrixoma. Cancer. $2001 \mathrm{Aug}$ 25;93(4):252-6.

14 Hawkes JE, Woodcock J, Christensen LC, Duffy KL. Giant pilomatricoma with angiomyxoid stroma: unusual presentation of a benign tumor. JAAD Case Rep. 2015 Jul; 1(4):169-71.

15 Mathen LC, Olver JM, Cree IA. A large rapidly growing pilomatrixoma on a lower eyelid. Br J Ophthalmol. 2000 Oct;84(10):1203-4. 